\title{
Study on Biotoxicity of Sludge Stabilized by Sludge Drying Reed Bed
}

\author{
Yao-bo Liu ${ }^{\text {a }}$, Yu-bo Cuib, ${ }^{\text {, }}$, Zhuma Luosang $^{c}$, Xin Li ${ }^{d}$, Wen-juYang ${ }^{\mathrm{e}}$ and Jun-yu \\ Liang $^{f}$
}

College of Environment and Resources, Dalian Minzu University, Dalian, China

${ }^{*}$ Corresponding author

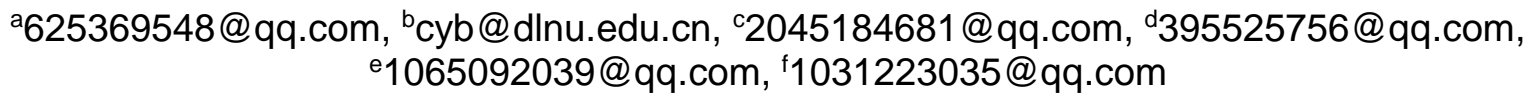

Keywords: Sludge drying reed bed; Excess sludge; Luminescent bacteria; Biological toxicity Abstract. The sources of urban sewage are complex that lead to harmful substances such as heavy metals et al existing in the excess sludge. If the sludge is directly discharged into the environment without treatment, it will cause secondary pollution to the environment. The paper used the photogenic bacteria to test the changes of the biotoxicity of the sludge stabilized by sludge drying reed bed at different times under different drying conditions, investigated the efficacy of the toxic substances degradation and transformation in the process of sludge stabilization by reed bed comparing with the conventional drying bed. The results show that the biotoxicity of stabilized sludge in the reed bed under the condition of ventilation reduced more comparing to the other conditions; meanwhile, the biological toxicity of the sludge in the bottom layer changed from high toxicity to low toxicity. As a result, the sludge stabilized by reed bed can significantly reduce its ecological risk and improve its agricultural safety.

\section{Introduction}

The generation of excess sludge in the treatment of sewage is inevitable, and usually sludge contains persistent organics such as heavy metals and antibiotics. If the surplus sludge is directly used for agriculture, these pollutants will be transferred to the planted crop and then enter the human body through the food chain, then harm human health [1]. At present, China mainly adopts composting methods for the treatment of excess sludge, however, due to the fact that China's sludge composting technology is not yet mature and the facilities are not perfect, only a few can be successfully operated [2].Repeated use of sludge will lead to the accumulation and enrichment of heavy metals in the soil, thus impairing the biological characteristics of the soil may also have an adverse effect on the soil microbial community structure and plant growth [3].Therefore, at this stage, the assessment of the type of pollution and the availability of the excess sludge has attracted much attention [4-5].Sludge eco-stabilization is a new sludge treatment method that utilizes artificial wetland (sludge drying reed bed) technology to stabilize sludge [6].The development of this technology originated in Europe and was widely used in Denmark, Spain, and the United States, while China and some Asian countries are in the stage of research [7-10].Ecologically stabilized sludge products can be used as agricultural fertilizers [7].

This article will use the luminescent bacteria test method, to study the biological toxicity changes of sludge dried reed bed during the run and stationary phases.

\section{Experimental Part}

Operation of Sludge Drying Reed Bed. The reed bed is plant reeds in the artificial wetland filler layer. Wetland Plant Reeds have unique characteristics that can transfer oxygen to the root system and reduce the physical and chemical hazards of anaerobic soils [11], the shaking of the foliage during the growth of the reed can promote the dehydration and stability of the sludge. Excess sludge can be converted into a substrate that is similar to soil and has agricultural value [12].

The excess sludge will contain toxic and harmful substances, growing in this adverse environment, the roots of reeds are affected by toxic and harmful substances. At the same time, the sludge will also 
contain nitrogen, phosphorus, potassium and other trace elements necessary for plant growth. The reed root system releases some secretions to promote the stability and harmlessness of the sludge. Stable sludge will become a substitute for agricultural fertilizer [13].

Experimental Materials and Methods. Sample collection and preservation. The experimental system consists of sludge pump, mud box, and sludge drying beds, which compose of three parts, i.e. units I,II, and III ( $3.0 \mathrm{~m} \times 1.0 \mathrm{~m} \times 1.3 \mathrm{~m}$ each). Among them, Ventilation pipes were set up in Units I and II, Reeds were planted in Units II and III, and each unit was an independent operation system [14].The system has been running for four years, during the first three years of operation, excess sludge was regularly input into the system, the last year was the stable period of the system. Sludge requires stratified sampling, surface layer: sediment interface to the above $5 \mathrm{~cm}$ range, bottom layer: $10-15 \mathrm{~cm}$ above the sediment interface. The retrieved sample should be sealed in a sealed bag.

Sample Detection. Each unit is divided into surface mud and sediment, and there are six samples of three units, weigh $10 \mathrm{~g}$ on each sample, the weighed sample was placed in a $100 \mathrm{ml}$ beaker and $40 \mathrm{ml}$ of $2 \% \mathrm{NaCl}$ was added, stir with magnetic stirrer for 20 minutes, then let it stand for 10 minutes, take $10 \mathrm{ml}$ supernatant and vacuum filter it for use. Separately take $1 \mathrm{ml}$ of the supernatant while adding 0.1 $\mathrm{ml}$ of osmotic pressure adjustment solution and shake gently, blank control group is $1 \mathrm{ml}$ deionized water, remove the lyophilized bacteria and immediately add the bacterial resuscitation solution and gently shake it for use, add $0.5 \mathrm{ml}$ bacterial resuscitation solution to the above 7 samples, biological toxicity tests were performed after 15 minutes at $20^{\circ} \mathrm{C}$.

\section{Results and Discussion}

Biological Toxicity of Sludge in Different Sludge Drying Beds. Figure 1 shows the trend of changes in the inhibitory rate of luminescent bacteria in the first bed sludge in 2016, Figure 2 shows the trend of inhibition rate of luminescent bacteria in reed beds of No. 2 ventilation structure in 2016,Figure 3 shows the trend of inhibition rates of luminescent bacteria in bed No. 3 of dried reed beds without ventilation structure in 2016,Figure 4 is a comparison of the changes in the inhibitory rate of luminescent bacteria in sludge on the surface of three drying beds in 2106,Figure 5 is a comparison of the changes in the inhibitory rate of luminescent bacteria in sediments of 3 dry reeds in 2106.Using light-emitting bacteria to detect the biological toxicity of samples, its calculation formula is: Luminescence inhibition rate of the sample: $\mathrm{I}(\%): \mathrm{I}=(\mathrm{R} 0-\mathrm{R}) / \mathrm{R} 0 \times 100 \%$. The higher the luminescence inhibition rate, the greater the biological toxicity of the test sample.

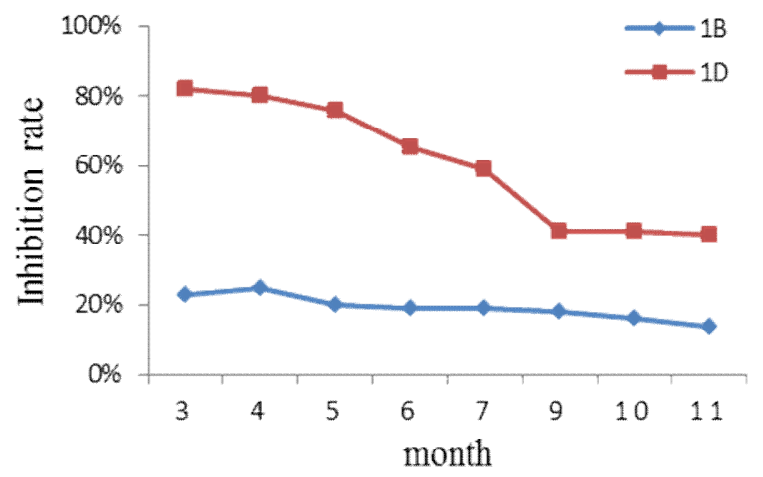

Fig. 1 Luminescent bacteria inhibition rate on bed 1

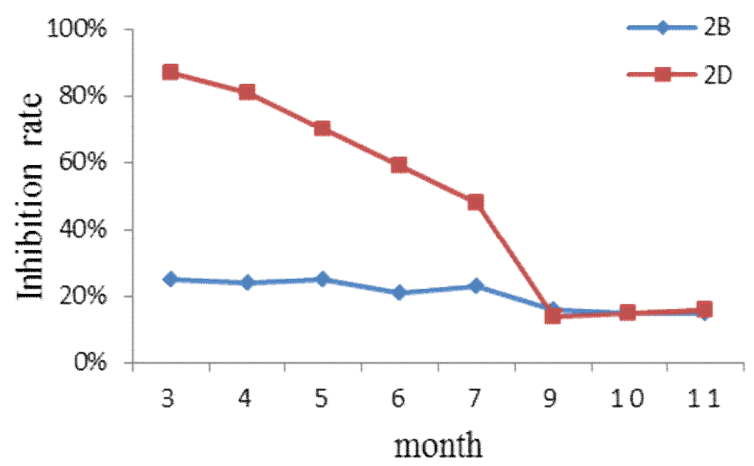

Fig. 2 Luminescent bacteria inhibition rate on bed 2

Figures 1, 2 and 3 show the inhibition of luminescent bacteria by surface mud and sediment in three different desiccant beds from March to September, it can be seen that the biological toxicity of sediment is significantly higher than that of surface sludge, and the surface mud is always in a low-toxic state. $\mathrm{NaCl}$ as a biological toxicity test extract, most of the toxic substances extracted are water-soluble inorganic toxic substances and heavy metals. The long-term accumulation and enrichment of these substances may be the reason for the higher biological toxicity of the sediment. 


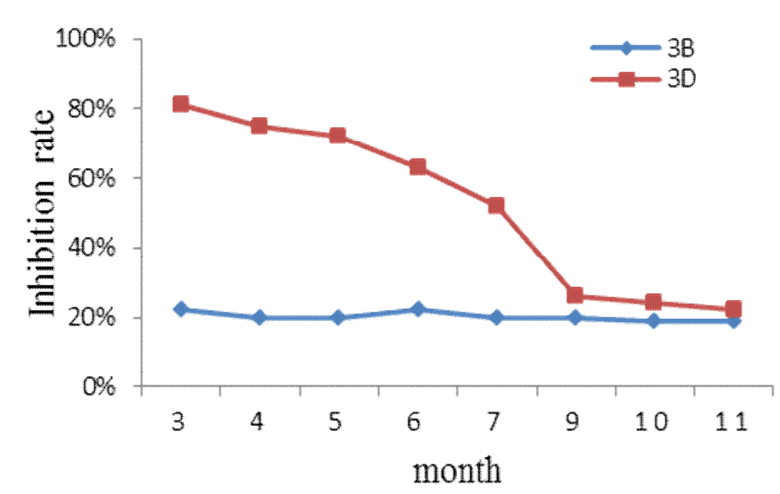

Fig.3 Luminescent bacteria inhibition rate in bed 3

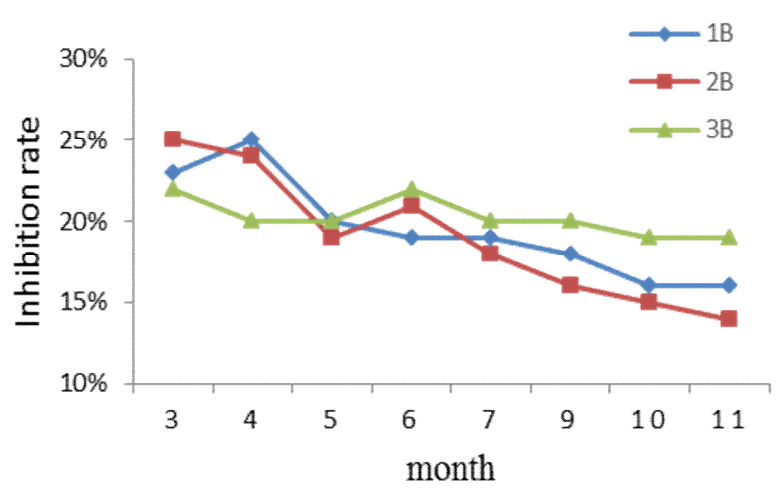

Fig. 4 Luminescent bacteria inhibitory rate of the surface sludge in three reed beds in the fourth year

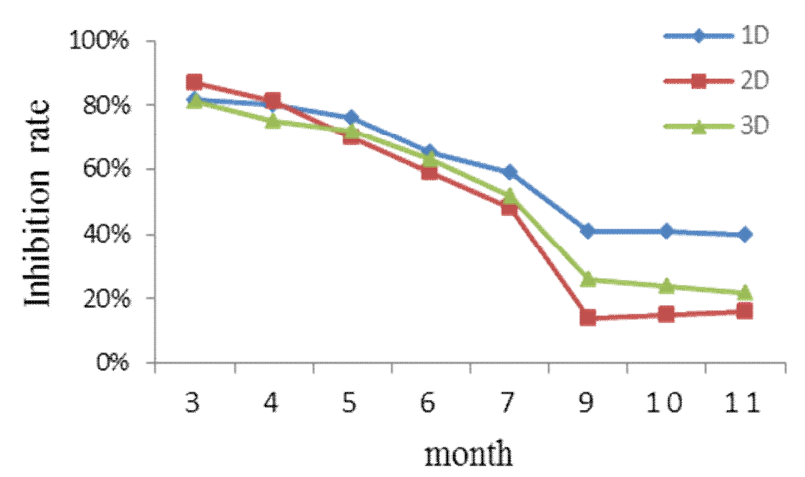

Fig.5 Luminescent bacteria inhibitory rate of the bottom sludge in three reed beds in the fourth year

With the change of time and season, the biological toxicity of surface mud slowly decreased from March to September, September to November tends to be stable, the biological toxicity of the bottom mud varies greatly with time and season, from the beginning of March, the bio-toxicity of the sediment has shown a clear downward trend, from the original high-toxicity state to the low-toxicity state near the surface of the soil. Especially in July-September, the bio-toxicity of sediment decreased the most in the summer with the highest temperature. From this speculation, in the sludge drying reed bed system, through the metabolic process of reeds and microorganisms, some toxic substances in the sludge can be decomposed or converted into non-toxic substances, with the increase of temperature, the strength of reeds and the activity of microorganisms will also increase, thereby reducing the biological toxicity of sludge and increasing the utilization rate of sludge.

Figure 4 and Figure 5 compare the suppression rates of luminescent bacteria in the surface mud and bottom mud of the three beds in the sludge stabilization period in 2016. As can be seen from Figure 4, the surface sludge changes little during the entire sludge stabilization period, the biological toxicity has been in a low-toxic state but it will float up and down. As can be seen from Figure 5, during the entire period of sludge stabilization, the inhibitory rate of sludge luminescing bacteria at the bottom of the three beds showed a significant downward trend, sludge biological toxicity of No. 2 and No. 3 beds is lower than that of No. 1 bed, the reason may be that the planted reed grows vigorously in the spring and summer seasons, through the metabolism and transformation of the reeds, the rate of reduction of the stabilized sludge toxicity is faster than that of a conventional sludge drying bed. The bio-toxicity of sludge in bed No. 2 was lower than that in bed No. 3, and the downward trend was most obvious, this may be due to the fact that more oxygen enters the bottom sludge system after ventilating the No. 2 bed, while the reed roots and surrounding microorganisms can obtain more oxygen. Under aerobic conditions, the metabolism rate of various microorganisms and roots of reeds is faster than that of anaerobic, therefore, the rate of degradation of toxic substances in the sludge is also highest.

Bio-toxicity Changes of Sludge in Sludge Drying Bed in Different Periods. Figure 6 shows the change trend of inhibition rate of luminescent bacteria in the surface layer of sludge in reed bed 2 in 
the year of 2015 and 2016. Figure 7 compares the changes in inhibition rates of luminescent bacteria in the bottom layer of sludge.

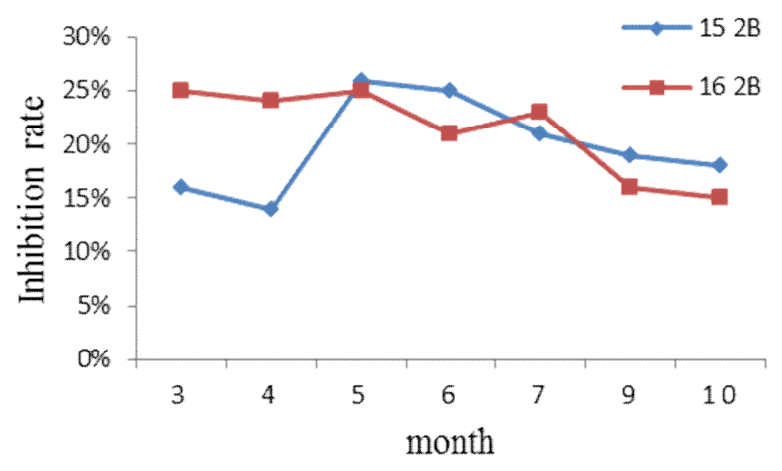

Fig. 6 Contrast of inhibitory rate of luminescent bacteria of surface sludge of bed 2 in 2015 and 2016 years

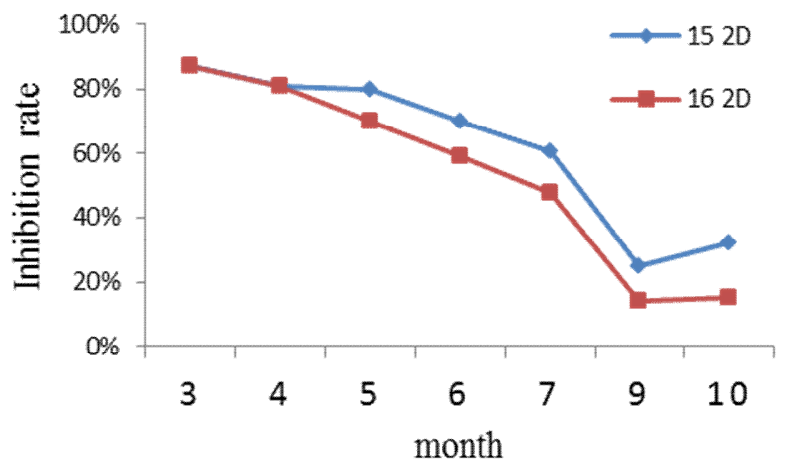

Fig. 7 Comparison of inhibitory rate of luminescent bacteria in bottom sludge of bed 2 in 2015 and 2016 years

Through the comparison and analysis of the previous data, it is preliminarily believed that the No. 2 bed planted with reeds and provided with a vent pipe has the best effect on reducing the biological toxicity of sludge. So, compare the data of the operation period of the No. 2 bed in 2015 with the data of the sludge stabilization in 2016, analyze the degradation and transformation of toxic substances in sludge reed beds in the stable period of sludge. It can be seen from Figure 6 that the bio-biological toxicity of the surface sludge is always in a low-toxic state during the system operation period and the sludge stabilization period, both have a slight fluctuation but the fluctuations in the sludge stabilization period have become more stable, it may be due to no new toxic substances entering the system continuously during the sludge stabilization period. As can be seen from the Figure7, the stabilization period bottom sludge bio-toxicity is significantly lower than that of the system operation period, And from March to September, the declining trend of biological toxicity is even more pronounced, it can be considered that without external toxic substances continuously entering the system, the toxic substances will be gradually degraded and transformed by reeds and microorganisms as time passes, thereby reducing the biological toxicity of the excess sludge and improving the availability of the excess sludge.

\section{Conclusions}

From the experimental data analysis, it can be found that the bio-toxicity of the surface sludge under the different drying conditions changes little with seasons and has been in a low-toxic state, the bio-toxicity of the bottom sludge will decrease as the temperature increases, since the reed and micro-organisms have the strongest metabolic capacity in the high-temperature season, it has the strongest ability to degrade and transform toxic substances and thus reduce the biological toxicity of sludge. Compared with three different drying beds, the No. 2 bed planted with reeds and equipped with a vent pipe has the highest ability to degrade and transform toxic substances, under aerobic conditions, the metabolic rate is greatly increased, and the toxic substances can be degraded and converted better, which results in a reduction in the biological toxicity of the sludge. Through the sludge stabilization period, the sludge biological toxicity of the sludge drying bed is greatly reduced, especially the biological toxicity of the bottom sludge is changed from high toxicity to low toxicity, which greatly improves the agricultural safety of sewage sludge. It can be seen that the sludge dried reed bed plays a role in reducing the biological toxicity of the sewage sludge, and the later experiments should further analyze the factors that affect the biological toxicity of the sludge, and to study better ways to reduce the biological toxicity of sludge to improve the agricultural safety of the sludge, and to better achieve the recycling of resources. 


\section{Acknowledgements}

The research was financed by the National Natural Science Foundation of China and the Fundamental Research Funds for the Central Universities in China.

\section{References}

[1] Y.A. Zhang, D. Gao, T.B. Chen, G.D. Zheng and Y.X. Li: Ecology and Environment Vol. 15 (2006), p. 234-238

[2] J. Liu: Journal of Yangtze University(Natural Science Edition) Vol. 8 (2011), p. 246-248

[3] L. Zhang, F.B. Song and X.B. Wang: Ecology and Environment Vol. 13 (2004), p. 258-260

[4] J.L. Yao, H.Y. Wang, Y.J. Yu, Q. Wang and X.R. Wang: Research of Environmental Sciences Vol. 23 (2010), p. 696-702

[5] R.Y. Shen, Y.M. Luo, G.Y. Zhang, Z.G. Li, Y. Teng and W. Qian: Soils Vol. 38 (2006), p. 539-546

[6] H.J. Sun, Y.B. Cui, F. Wang, Y.H. Liu and S.X. Bao: Journal of Safety \& Environment Vol. 11 (2011), p. 81-84

[7] S. Nielsen and N. Willoughby: Water and Environmental. Vol. 19(2005), p. 296-305

[8] E. Uggerri, I. Ferrer, J.Molist and J. Carcia: Water Research. Vol. 45(2011), p. 573-582

[9]A.I. Stefanakis, C.S. Akratos, P. Melidis and V.A. Tshrintzis: Hazardous Materials. Vol. 172(2014), p. 1122-1130

[10] Y.B. Cui, H.J. Sun, M.L. Yang and Y.H. Liu : Residuals Science \&Technology. Vol. 9(2012), p. 47-53

[11] D.P. Wei, Y.B. Ma, S.B. Chen and J.G. Sun: Journal of Ecology. Vol. 24(2008), p. 1413-1421

[12]W. Larcher: Physiological plant ecology. Vol. 590(1995), p. 1313-30

[13] H.J. Sun, Y.B. Cui, S.H. Yang, Y.H. Pu and Y.X. Yuan: Environmental Engineering, Vol. 31(2013), p. 117-121

[14]Y.B. Cui, F. Wang, N. Jiang, M.L. Yang and H.J. Sun: Journal of Environmental Engineering. Vol. 6(2012), p. 2522-2526 